Journal of Biomedical and Pharmaceutical Research

Available Online at www.jbpr.in

CODEN: - JBPRAU (Source: - American Chemical Society)

PubMed (National Library of Medicine): ID: (101671502)

Volume 8, Issue 3: May-June: 2019, 74-78

ISSN (Online): 2279-0594

ISSN (Print): 2589-8752

Research Article

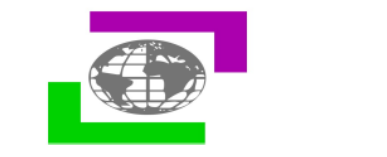

\title{
PRESCRIPTION PATTERN OF DIURETICS IN A TERTIARY CARE HOSPITAL
}

\author{
P G Chithara*, Dr. Yogananda R, Dr. Bharathi DR
}

SJM College of Pharmacy, Chitradurga -577502

Article Info: Received 14 May 2019; Accepted 11 June. 2019

DOI: https://doi.org/10.32553/jbpr.v8i3.614

Address for Correspondence: P G Chithara, Pharm. D Intern, SJM College of Pharmacy, Chitradurga -577502

Conflict of interest statement: No conflict of interest

\section{ABSTRACT:}

Diuretics are drugs that increase the rate of urine flow; clinically useful diuretics also increase the rate of excretion of $\mathrm{Na}+$ (natriuresis) and an accompanying anion, usually $\mathrm{Cl}$. Diuretics are a mainstay of therapy for a wide variety of diseases ranging from hypertension to the nephrotic syndrome.

Objective: To study the prescribing patterns of diuretics in General Medicine and ICU. To assess the drugdrug interaction of diuretics. To study the route of administration of diuretics.

Materials and methods: A prospective observational study was conducted over a period of six months at general medicine and ICU department of Basaveshwara Medical College and Hospital and Research Centre, Chitradurga.a otal of 100 in-patients are included as study subject.

Results: Mostly prescribed diuretic in this study were furosemide (52.9\%), followed by mannitol (28.1\%), spironolactone (11.57\%), torsemide (5.79\%), amiloride (0.82\%) and hydrochlorothiazide (0.82\%). Out of 100 prescriptions $84.4 \%$ of diuretics prescribed in intravenous route, $15.6 \%$ of diuretics prescribed in oral route. Out of 100 prescriptions total 89 drug interactions with diuretics are found. In that $2.3 \%$ major interactions and $67.4 \%$ moderate interactions and $30.3 \%$ minor interactions are found.

Conclusion: Prescription monitoring helped to reduce the diuretic usage errors with respect to dose and drug-drug interaction with other prescribed drugs to provide better patient care.

Keywords: prescribing pattern, drug-drug intraction, diuretics

\section{INTRODUCTION}

Diuretics are drugs that increase the rate of urine flow; clinically useful diuretics also increase the rate of excretion of $\mathrm{Na}^{+}$(natriuresis) and an accompanying anion, usually $\mathrm{Cl}^{-}$. Most clinical applications of diuretics aim to reduce extracellular fluid volume by decreasing total-body $\mathrm{NaCl}$ content. Although continued administration of a diuretic causes a sustained net deficit in total-body $\mathrm{Na}^{+}$, the time course of natriuresis is finite because renal compensatory mechanisms bring $\mathrm{Na}^{+}$ excretion in line with $\mathrm{Na}^{+}$intake, a phenomenon known as diuretic braking. ${ }^{1}$

Diuretics are a mainstay of therapy for a wide variety of diseases ranging from hypertension to the nephrotic syndrome. ${ }^{2}$ Diuretics are the drugs of choice for congestive heart failure, preferably combined with an ACEI .For patients with resistance to oral furosemide, bumetanide is an alternative loop-diuretic due to its better bioavailability. The indications for daily diuretic use may be inappropriate, e.g. Postural oedema, Climacteric complaints, Mastalgia, and the Premenstrual syndrome. ${ }^{3}$

Loop diuretics inhibit the $\mathrm{Na} / 2 \mathrm{Cl}^{-} / \mathrm{K}$ co-transporter in the thick ascending loop of Henle, resulting in decreased urine sodium and chloride reabsorption with natriuresis and diuresis. ${ }^{4}$. Generalized edema can develop in nephrotic syndrome, chronic kidney disease, heart failure, and liver cirrhosis. Usually patients with edema respond to dietary sodium 
restriction in combination with a loop diuretic. However, some patients become resistant to diuretics. Diuretic resistance is defined as failure to achieve the therapeutically desired reduction in edema even when a maximal dose of diuretic is employed. ${ }^{5}$

Guidelines for the treatment of hypertension recommend that thiazide diuretics should be the preferred drugs in most hypertensive patients, including in diabetics, either alone or combined with drugs from other classes. ${ }^{6}$ Diuretic drugs are prescribed for ankle oedema. Ankle oedema is a misleading sign only occasionally being associated with heart failure hence withdrawal of diuretics has been suggested for elderly patients with ankle oedema provided that the oedema is not caused by cardiac, renal, or hepatic insufficiency .

Acute decompensated heart failure (ADHF) is predominantly a disease of fluid overload and the primary therapeutic objective of most ADHF hospitalizations is fluid removal, with intravenous loop diuretics. ${ }^{8}$ Of all drugs for HF treatment, diuretics are therapeutically superior in their efficacy in relieving clinical symptoms and signs. They are recommended in the presence of congestion until achievement of a euvolemic state and subsequently to prevent the recurrence of fluid retention. ${ }^{9}$

\section{MATERIALS AND METHODS}

This prospective observational study was conducted at general medicine department in Basaveshwara Medical College Hospital and Research Centre, Chitradurga over a period of six months (November 2017 to April 2018 ). The study was approved by the institutional ethical committee of SJM College of Pharmacy, Chitradurga. All the in-patients of general medicine and ICU who are treated with diuretics are enrolled.

\section{INCLUSION CRITERIA:}

- Patients who are taking diuretics.

- Patient of both gender admitted in medicine and ICU

- Patients who are willing to give informed consent

EXCLUSION CRITERIA:

- Psychiatric patients

- Out patients.

- Paediatrics
Ethical approval:

The study was approved by the Institutional Ethical Committee of SJM College of Pharmacy, Chitradurga.

Vide number: SJMCP/PHARM D /26/17-18 (ANNEXURE -1)

Sources of data:

- Medical records of the patients.

- Patient /care taker interview.

Statistical analysis:

The collected data was complied, entered and analysed in Microsoft Excel spreadsheet 2007.

\section{RESULTS}

A prospective observational study carried out in 100 patients admitted in General Medicine and ICU of Basaweswara Medical College Hospital.

\section{Distribution of patients according to age}

Out of 100 patients maximum number of patients comes under the age of $71-80$ (26\%) and minimum number of patients comes under the age of 21-30 (4\%) and 31-40(4\%).

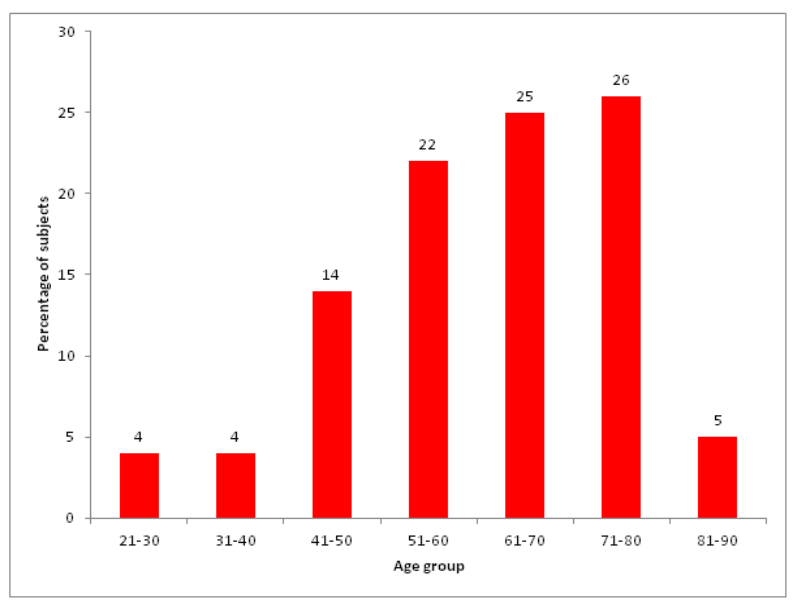

\section{Distribution of patients according to gender}

Out of 100 patients 63 patients are male and 37 patients are female.

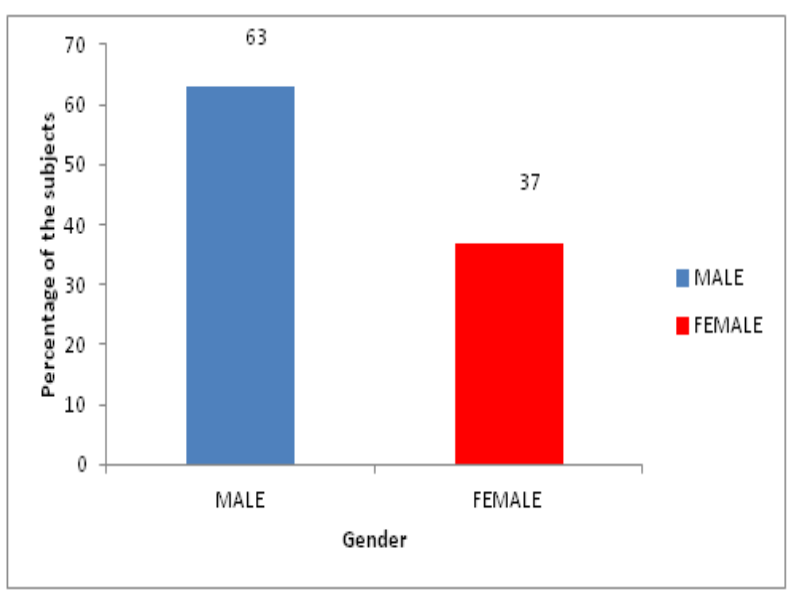




\section{Pattern of diuretic prescription}

Mostly prescribed diuretic in this study were furosemide $(52.9 \%)$, followed by mannitol $(28.1 \%)$, spironolactone(11.57\%), torsemide (5.79\%) amiloride $(0.82 \%)$ and hydrochlorothiazide $(0.82 \%)$. Diuretic use pattern is shown in table 3 and depicted in fig 3.

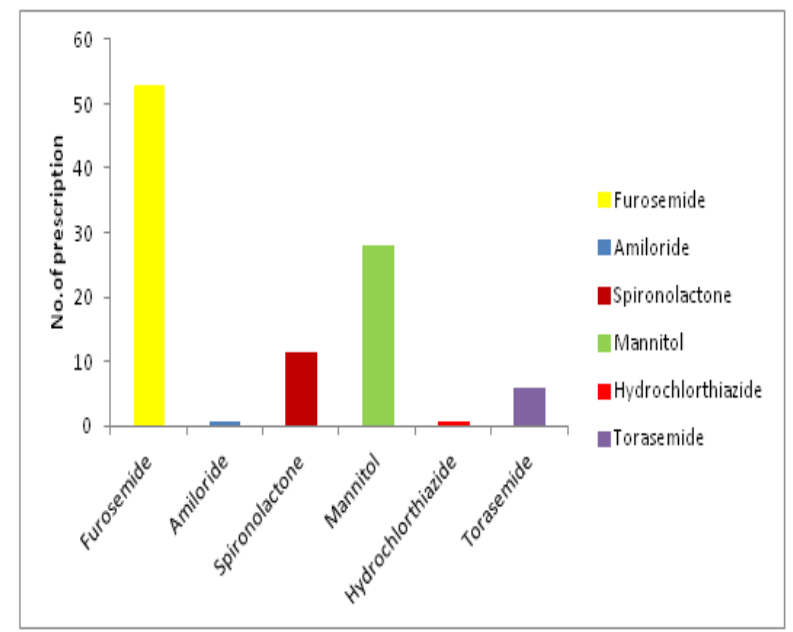

\section{Distribution of patient based on number of diuretics per prescription}

Among 100 patients, 81 patients were prescribed with single diuretic, 17 with two diuretics and 2 with three diuretics. The details are given in table 4 and graphically represented in fig 4 .

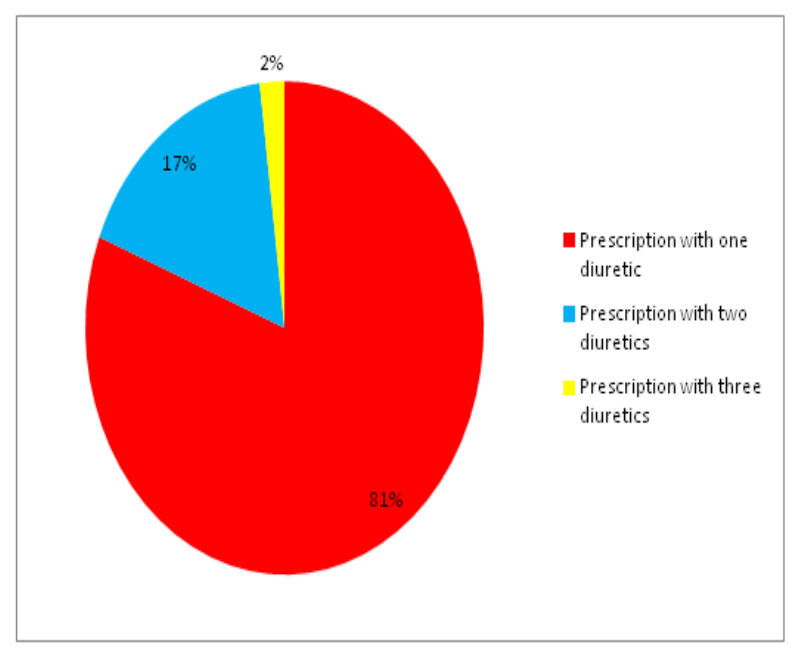

\section{Distribution according to route of administration.}

Out of 100 prescriptions $84.4 \%$ of diuretics prescribed in intravenous route, $15.6 \%$ of diuretics prescribed in oral route. The details are shown in table 6 and graphically represented in fig 5 .

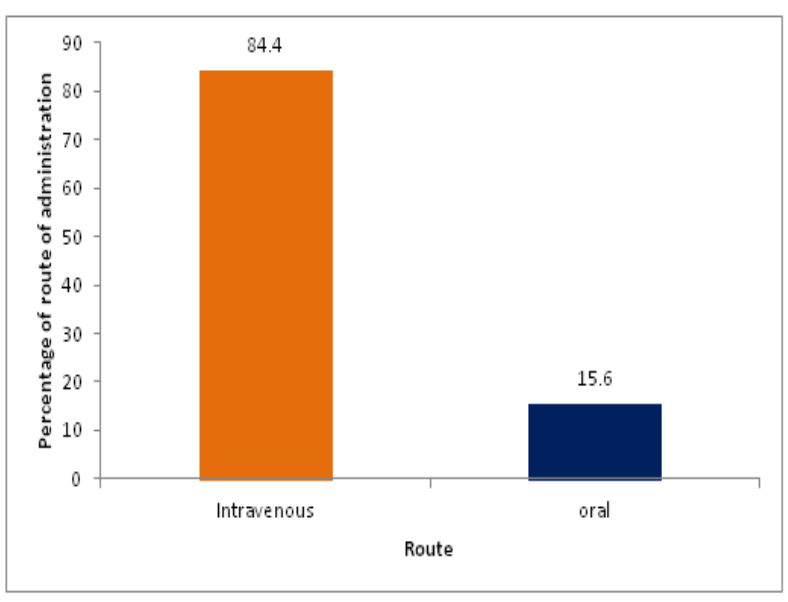

\section{Distribution of drug interactions.}

Out of 100 prescriptions total 89 drug interactions with diuretics are found. In that $2.3 \%$ major interactions and $67.4 \%$ moderate interactions and $30.3 \%$ minor interactions are found. The details are shown in table 7 and graphically represented in fig 6.

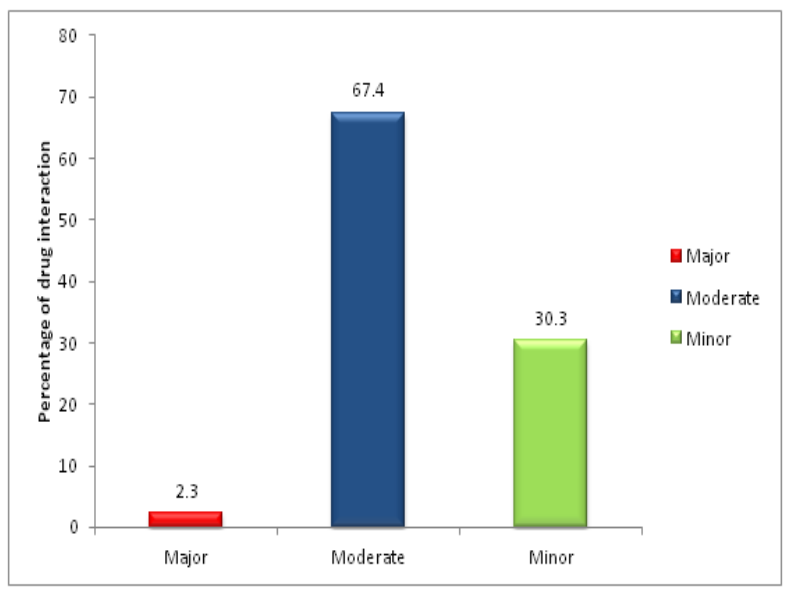

\section{DISCUSSION}

The study enrolled 100 patients out of which maximum number of patients comes under the age of 71-80 and minimum number of patients comes under the age of 21-30 and 31-40. A similar study done by Shivashankar $V$ et al., and found the result maximum number of patients comes under age group of 50-59 yrs minimum number of patients comes under age group of below $30 \mathrm{yrs}$. This result was not in concordance with present study.

In the present study with 100 patients $63 \%$ patients are male and $37 \%$ patients are female. A similar study done by Shivshankar $V$ et al., shows that among them $64.66 \%$ were males and $35.33 \%$ were females. This result is same as current study. 30 
Mostly prescribed diuretic in present study were furosemide $(52.9 \%)$, followed by mannitol $(28.1 \%)$, spironolactone(11.57\%), torsemide (5.79\%) , amiloride $(0.82 \%)$ and hydrochlorthiazide $(0.82 \%)$. A similar study conducted by Straand $J$ and Rockstad K, found out the result that Furosemide was prescribed most frequently (48.7\%) followed by the compound diuretic of hydrochlorothiazide and amiloride (26.4\%), thiazides and related drugs (13.0\%), and spironolactone (5.8\%).3

In this study out of 100 prescriptions total 89 drug interactions with diuretics are found. In that $2.3 \%$ major interactions and $67.4 \%$ moderate interactions and $30.3 \%$ minor interactions were found. A similar study conducted by Carter BL et al., results shows that $8.2 \%$ level $1,22.5 \%$ level 2, 6.4\% level 3,36.2\% level 4 , and $26.7 \%$ level 5 interactions.[1=major, $2=$ moderate, $3=$ minor (levels 1, 2, or 3 could be suspected or probable interaction), $4=$ major $/$ moderate (with only possible documentation of the interaction), and 5 $=$ either minor and possible interaction or major/moderate but unlikely documentation of an interaction]. The result is not in concordance with present study. 44

In the present study among 100 patients, 81\% patients were prescribed with single diuretic, $17 \%$ with two diuretics and $2 \%$ with three diuretics. Similar study conducted by Singh $\mathrm{H}$ and Johnson ML shows that $39.3 \%$ patient on one diuretic $18.3 \%$ patients on two diuretics $11.0 \%$ on three diuretics. This result is similar to current study. 45

Out of 100 prescriptions $84.4 \%$ of drugs comes under intravenous route, $15.6 \%$ of drugs comes under oral route. A similar study conducted by Straand J and Rockstad K., found the result that oral (87.6\%), intravenous (12.4\%). This result is not in concordance with current study.

\section{CONCLUSION}

With the result obtained the following conclusions are made;

- Mostly prescribed diuretic in present study was furosemide, and least prescribed was amiloride and hydrochlorothiazide.

- Age group of 71-80 found more in the study. Male patient were more when compared to female.
- Intravenous administration is most preferable route.

- Mostly found drug -drug interaction is moderate type.

- Prescription monitoring can reduce the diuretic usage errors with respect to dose and drug-drug interaction with other prescribed drugs to provide better patient care. Present study provides an idea for conducting Pattern of prescription on diuretic drugs at $\mathrm{BMCH} \& \mathrm{RC}$ and future studies are needed for the improvement in more diuretic drug use.

\section{ACKNOWLEDGEMENT:}

It is a pleasure and privilege to express my deep sense of thanks and indebtedness to the management of SJM College of Pharmacy Karnataka, dr. Yogananda $r$, professor and hod ,dept of pharmacy practice and Dr Bharathi DR , Principal of SJM College of Pharmacy for giving the consent and facilities to carry out this work

\section{REFERENCE}

1. Jackson EK. Drugs Affecting Renal and Cardiovascular Function. In, Goodman and Gillman (ed). Manual of Pharmacology and Therapeutics,11th edition. New York, McGraw-Hill,2005;477-498.

2. Arampatzis $S$, Funk $G C$, Leichtle $A B$, Fiedler GM, Schwarz C, Zimmermann H,Exadaktylos1 AK. Impact of diuretic therapy-associated electrolyte disorders present on admission to the emergency department: a cross-sectional analysis.BMC medicine 2013;11(83):1-6.

3. Rockstard K, Straand J. Are Prescribing Patterns of Diuretics in General Practice Good Enough, A Report from the More \& Romsdal Prescription Study. Scand J Prim Health Care 2016; 15(12):10-15.

4. Felker GM, Mentz RJ. Diuretics and Ultrafiltration in Acute Decompensated Heart Failure. J Am Coll Cardiol 2012;59(24): 21452153.

5. Hoorn EJ, Ellison DH. Diuretic Resistance. Am J Kidney Dis. 2017;69(1):136-142.

6. Shastry R, Adhikari MR, Ullal SD, Kotian S. Usage of Diuretics Among DiabeticHypertensive Patients. AJMS 2015;6(2):14-17

7. Jonge JW, Knottnerus JA, van Zutphen WA, Struijker-Boudier HA, de Bruijne GA. Short 
P G Chithara et al., Journal of Biomedical and Pharmaceutical Research

term effect of withdrawal of diuretic drugs prescribed for ankle oedema. Br Med J1994; 5(12):1-5.

8. Aroson D, Burger AJ .Diuretic Response: Clinical and Hemodynamic Predictors and Relation to Clinical Outcome. J Card Fail 2016; 22(3):265-270.

9. Testani JM, Brisco MA, Turner JM, Spatz ES, Bellumkonda L, Parikh CR, Tang WH. Loop Diuretic Efficiency A Metric of Diuretic Responsiveness with Prognostic Importance in Acute Decompensated Heart Failure. PLoS One 2016; 10(16): 261-270.

10. Thripadi KD.Diuretics .In Essentials of Medical Pharmacology 6th edition. New Delhi, Jaypee Brothers Medical Publishers; 2008:561-573.
11. Shah SU, Anjum S, Littler WA. Use of diuretics in cardiovascular disease: (2) hypertension. $\mathrm{Br}$ Med J 2003;80:271-276.

12. Shaughnessy KM . Kidney and genitourinaary tract. In, Bennet PN and Brown MJ Clinical Pharmacology, 9th edition. Spain , McGrawHill Medical, 2003;529-548.

13. Roush GC and Sica DA. Diuretics for Hypertension: A Review and Update. Am J Hypertens 2016;1130-1137.

14. Slaughter JL, Stenger MR, Reagen PB. Variation in the Use of Diuretic Therapy for Infant with Broncho pulmonary Dysplasia. J Peadiatr 2013;131:716-723.

15. Bernstein LM, Blumerg B, Arkin MC. Osmotic Diuretic Treatment of Refractory Edema. J Am Heart Assoc 1958;17:1013-1020. 